\title{
The Adoption of 4G Mobile Network Services in Klang Valley
}

\author{
A. H. Nor Aziati ${ }^{+}$, Ang Siew Hoon, Nor Hazana Abdullah, Yunos Ngadiman and Ahmad M. F. \\ Department of Production and Operation Management, Faculty of Technology Management and Business, \\ Universiti Tun Hussein Onn Malaysia, Malaysia
}

\begin{abstract}
This research highlighted the $4 \mathrm{G}$ mobile network adoption Klang Valley, Malaysia. Mobile penetration rate in all states are high which implies multiple subscriptions. Despite this, the reciprocal implication is that there remains a significant low adaption level of $4 \mathrm{G}$ service. High adoption of $4 \mathrm{G}$ was reported from developed countries within the context of higher education learning to support the learning process. Thus, this study attempt to determine the adoption factors of $4 \mathrm{G}$ mobile services in the Klang Valley. Besides that, the influence of $4 \mathrm{G}$ demographic profile towards adoption level also had been determined in the study. This study integrates perceived enjoyment to Technology Acceptance Model (TAM) which had been considered the most beneficial for expecting the use of such technology. The study employed quantitative approach using validated survey methods. A total of 95 respondents consisting of $4 \mathrm{G}$ users were selected by using the convenience sampling method. Independent variables constitute of perceived usefulness, perceived ease of use, attitude, and perceived entertainment value. Meanwhile, the dependent variable is behavioral intention to use. The findings revealed that the positive influence between the relationship of perceived usefulness, ease of use, entertainment value, attitude and behavioral intention. Furthermore, perceived entertainment value was the leading factor that influencing subscriber's intention. On the other hand, the demographic of subscribers are not significant influence to their intention to use 4G. This study provided information to service providers in order to reinforce the relative advantage and entertaining attributes to promote the adoption of $4 \mathrm{G}$.
\end{abstract}

Keywords: 4G adoption, mobile network, technology acceptance in Malaysia.

\section{Research Background}

Fourth Generation (4G) mobile networking is the evolution of mobile communication from $3 \mathrm{G}$ and WLAN [1]. The network was built with three technologies; LTE (Long Term Evolution), HSPA+ (High Speed Packet Access) and WiMAX (Worldwide Interoperability for Microwave Access). The significant feature of the $4 \mathrm{G}$ is the ability to transmit high quality video images and image transmission comparable in quality to high-definition television technology products [2]. The fast pace of modern life has improved work efficiency incomparable with the standard $3 \mathrm{G}$ just with up to $7.2 \mathrm{Mbps}$. Ideally, $4 \mathrm{G}$ system can download at a speed of $1 \mathrm{Gbps}$ [3], however, most of $4 \mathrm{G}$ can offer the estimated speed up to $75 \mathrm{Mbps}$. Based on Digitimes Research (2014) in ASEAN market, the total number of mobile communication subscribers will reach 744.3 million in 2016 , with $3 \mathrm{G}$ to account for $53.1 \%, 2 \mathrm{G}$ for $39.9 \%$ and $4 \mathrm{G}$ for $7 \%$, [4]. Yet, $4 \mathrm{G}$ subscribers are less than $10 \%$ of all mobile subscribers in Malaysia [4]. Nevertheless, according to [5] the mobile penetration rate in Malaysia is higher than the United States, Indonesia and world's average with 13 million of Malaysian subscribers are actively using mobile phones for social connectivity. One of the reasons of low level of $4 \mathrm{G}$ subscribers is the delayed rollout of broadband services, slower infrastructure growth and slower pace of adoption [6]. In Malaysia, 4G is commenced in 2013 with four major 4G provider companies; Maxis, Celcom, DiGi and U Mobile. According to information provided by [7], four service providers (Maxis, Celcom, Digi and U Mobile) have launched their 4G LTE services in 2013.

\footnotetext{
Corresponding author. Tel.: +60137668244.

E-mail address: aziati@uthm.edu.my.
} 
Despite the expansion of $4 \mathrm{G}$ areas and development of networks, $3 \mathrm{G}$ subscribers are still not switching to 4G due to poor networking coverage (especially rural area) [8], cost-saving and unexpected data speed. Due to the constraints, the $3 \mathrm{G}$ subscribers are still higher than $4 \mathrm{G}$ subscribers [9]. Although the coverage of $4 \mathrm{G}$ network is double expanded in Klang Valley, Johor, Penang, Sabah and Sarawak [10]. Yet, the overall coverage of $4 \mathrm{G}$ mobile services is limited in Malaysia [11]. Thus, the uncovered area of the broadband, especially in the rural area, the $4 \mathrm{G}$ subscribers will shift to $3 \mathrm{G}$ service. Additionally, $4 \mathrm{G}$ network will cause battery drainage [12]. Additionally, for those subscribers with frequent travelling, the changes of services between $3 \mathrm{G}$ and $4 \mathrm{G}$ networks is inconvenient [12]. Local organizations have been receptive and experimental in some case towards "transformational technology" such as cloud computing and analytics to hardness big data in the business world [13]. Subsequently the big data transmission is incremented; the consumption of battery in mobile phone is high. This will lead to the shorter battery life span. On the other hands, unstable 4G network connectivity is one of the issues. Additionally, based on research done by [14], the subscribers might not familiar with new technical properties and their purpose to use. In addition, low level adoption and exposure contributed of $4 \mathrm{G}$ broadband to this problem [15]. Ease of use of new technology is one of the factors that impact adoption. With the advantages of $4 \mathrm{G}$ support multimedia elements, thus in previous research, perceived entertainment value significantly affect intention to adopt technology [16]. Nonetheless, 4G mobile subscribers can only connect with $4 \mathrm{G}$ network by using designated of mobile phones [17]. $4 \mathrm{G}$ requires different frequencies than $3 \mathrm{G}$ for transmitting data. Hence, subscribers needed a compatible device to allow more network capacity for more data per subscribers [12].

Thus, this situation has left the vast amount of investment made by the providers to enhance their $4 \mathrm{G}$ services and expand the coverage areas in Malaysia. Malaysia Communications and Multimedia Commission (MCMC) [18] have reported that mobile capital expenditure per capita in Malaysia was above RM100 in year 2013. The sight from revenue, telecommunications sector were grown up to RM45.3 billion in 2013 that increased by $4.1 \%$ compared with 2012. Past scholars proposed the insights of the adoption of $4 \mathrm{G}$ mobile adoptions across the developed countries, while small numbers of published work on user perceptions of $4 \mathrm{G}$ has been found specifically Malaysia context (e.g.[18], [19] and [21]). Therefore, this study attempt to determine the adoption level of $4 \mathrm{G}$ mobile services among Malaysia subscribers especially in Klang Valley and the influence of demographic profile towards the $4 \mathrm{G}$ adoption level. The study focuses on the relationship between perceived usefulness, ease of use, entertainment value, attitude and users' intention toward 4G mobile services usage. This study will provide information in particular to mobile service providers in understanding of the adoption pattern and users satisfaction. Other than that, $4 \mathrm{G}$ service operators could increase their competitiveness if they were able to improve their performance in meeting consumer demand. Increased use and penetration of broadband $4 \mathrm{G}$ indirectly affect the economic growth. The paper is structured as follows. Relevant literature is reviewed and synthesized to develop a conceptual model, followed by methodology employed in the study. The results are then presented along with discussion. Finally, conclusion and implication are discussed.

\section{Literature Review}

\subsection{Technology Acceptance Model (TAM)}

There are numerous theoretical models have been proposed to predict user perceptions of new technologies. One of the common theories in technology adoption is Technology Acceptance Model (TAM). TAM has been extensively and successfully adapted to explain the processes of user's acceptance or reject new technology, especially in the fields of mobile services and technologies [9], [20], [23]. For example, [24] study has incorporated TAM in their study to determine factors affecting the intention to adopt LTE service at South Korea. Similarly, [1] has adopted TAM model for the case of 4G mobile services from the female student's perspective. Meanwhile, other researchers [25] studied the factors affecting students' intention to use mobile learning based by incorporating TAM. Davis [26] addressed this model by amended the weakness of the Theory of Reasoned Action (TRA). In TAM model, there was made rejection of subjective norm from TRA. This is due to least understood part in the subjective norm when conducted in measurement and conceptualization theory. Besides that, previous studies also confirmed that subjective norm had no 
significant effect towards intention [27]. This is because subjective norms relate to the social pressure perceived by an individual from important acquaintances for them to behave [28]. For most of Malaysia broadband users, the selection does not heavily influenced by close acquaintances, but rather the data rates, the quality of communications service and supplementary services. Thus the study remain five major variables in TAM which included Perceived Usefulness (PU), Perceived Ease of Use (PEOU), Attitude toward using, Behaviour Intention, Actual Behaviour. The selection of TAM is in line with some positive results that have been shown by several researchers in the context of Malaysia such as [21], [9] and [1]. Most researchers indicated that perceived ease of use and perceived usefulness have significant and positive effects on the adoption of mobile broadband in Malaysia. Nonetheless, Malaysian still prefer mobile network that offered affordable and attractive packages. In contrary, research done by [29] found insignificant relationship between perceived ease of use and perceived cost towards behavioural intention. Apart from original TAM model, many researchers extend the TAM since most of $4 \mathrm{G}$ users switch to $4 \mathrm{G}$ for video streaming and multimedia purposes. Reynolds [30] proposed the extension of TAM by adding the experience factors with the existing TAM as the basic theoretical frame. The researcher proposed perceived enjoyment to the TAM for determining the subscribers' intention to use of $3 \mathrm{G}$ mobile [31]. Similarly, [1] research proposed model based on TAM for 4G adoption by incorporating perceived entertainment value. Hence, this study postulates that Behavioural Intention (BI) was influenced by several independent variables. These include adoption factors mentioned in TAM with the extended factor; perceived enjoyment.

\subsection{G Adoption Factors}

\subsubsection{Perceived usefulness}

Among the variables that influence the adoption of new technology is perceived usefulness (PU). Davis [26] defined perceived usefulness as "the degree to which a person believes that using a particular system would enhance his or her job performance". In this study, perceived usefulness is define as the extent to which individual believes that use of $4 \mathrm{G}$ mobile services will improve their communications performance. People are able to accomplish their task more quickly and effectively with the compatible devices. For example, online shopping can assists people gain information about the products or services immediately with the fast speed of mobile internet access [32]. Mostly, the past researchers have proven the positive influenced toward user's intention. Based on [33] study, they take on a new data set in measuring perceived usefulness and perceived ease of use for two different technologies. Park et al. [24] stated that perceived usefulness is a key determinant of user attitudes toward 4G LTE services and the crucial role of perceived usefulness in TAM. This study measure perceived usefulness with five items adapted from [34]. Hence, the study hypothesis;

$\mathrm{H}_{1}$ : Perceived usefulness has positive effects on attitude toward using the $4 \mathrm{G}$ mobile services.

$\mathrm{H}_{2}$ : Perceived usefulness has positive effects on behavioural intention of using the $4 \mathrm{G}$ mobile services.

\subsubsection{Perceived ease of use}

Davis, [35] defines the term as "the degree to which a person believes that using a particular system would be free of effort". The research on TAM had justified perceived ease of use will directly influence perceived usefulness and contributes to attitude. In broadband research, [36] reported that perceived ease of use has insignificant influences towards behavioural intention to use. This is because the targeted respondents are young generation hence they tend to be more familiar with using computer and internet technology. In contrary, the results of the research on $4 \mathrm{G}$ mobile services by [1] highlighted the significant relationships of the perceived ease of use among other variables in the model. In similar vein, Suki et al. [31] revealed the perceived ease of use was positively influenced towards behavioural intention to use. There are offered a vertically integrated, top-down, services provider tactic to deliver wireless internet services and hence $4 \mathrm{G}$ subscribers are easy to use or effortless to communicate to each other. According to [14] the perceived ease of use has strong influenced on the adoption in 3G. They suggested mobile specialists should maximize the convenience on newest mobile gadgets for consumers to utilize and support $4 \mathrm{G}$ mobile phone's technology. The previous studies reported contradict findings on the perceived ease of use towards usage level. Thus, the current study attempts to prove the relationship within Malaysia context. The study 
adapted six items of measurement for perceived ease of use from [1], [9]. Therefore, the next hypothesis is posited;

$\mathrm{H}_{3}$ : Perceived ease of use has positive effects on the behavioural intention of using the $4 \mathrm{G}$ mobile services.

$\mathrm{H}_{4}$ : Perceived ease of use has positive effects on the perceived usefulness of using the $4 \mathrm{G}$ mobile services.

$\mathrm{H}_{5}$ : Perceived ease of use has positive effects on the perceived entertainment value using the $4 \mathrm{G}$ mobile services.

\subsubsection{Attitude}

Attitude is defined as the degree to which an individual's attitude is disposed, favourably or unfavourably, towards the $4 \mathrm{G}$ mobile services usage. In the previous study of mobile advertisements promoting movies had mentioned that attitude of technology acceptance is measured by perceived usefulness and ease of use [37]. Mathieson [38] had revealed the effect of attitude on intention is vital. In similar vein, [39] proved that the role of attitude as a determinant of behaviour and attitude captures both affect and evaluation in social psychology. A total of five items were included in the study based from the validated measurement employed by [31], [1]. This leads to the following hypothesis;

$\mathrm{H}_{6}$ : Attitude has positive effects on behavioural intention of using $4 \mathrm{G}$ mobile services.

\subsubsection{Perceived entertainment value}

Perceived entertainment value is defined as spending time or having fun, particularly situations when access to wired entertainment appliances is not possible. Thong et al. [40] have reported a significant effect of perceived post-adoption enjoyment on the continued adoption of mobile internet services. Additionally, [41] claimed the loyalty of online game affected by perceived entertainment value. In [42] study also revealed that the mobile advertising perceived in entertainment and information has affected their attitude. The subscribers' perception of the entertainment value is positively influences their attitudes [43]. The researcher found perceived entertainment value was the essential factors in website usage and there is significant relationship towards attitude [44]. Six measurement items were adapted from [1]. The study hypothesized;

$\mathrm{H}_{7}$ : Perceived entertainment has positive effects on attitude toward using the $4 \mathrm{G}$ mobile services.

$\mathrm{H}_{8}$ : Perceived entertainment has positive effects on behavioural intention toward using $4 \mathrm{G}$ mobile services.

\subsubsection{Behavioral intention}

Behavioural intention to use an information system is a measure of the option that an individual will adopt the application [26]. Crucially, the measurement of an individual's intention to engage in behaviour is not easy in practical to obtain. Both theoretical and empirical support for a correlation between intention to engage in a particular behaviour and actual behaviour itself had shown by several researchers. Behavioural intention is adopted as an individual's intention to use 4G mobile services in order to maintain instrument brevity. Social influence was positively affects intention and use in the past study of the mobile phone messaging [45]. Three items were adapted from [34] since the similar context of study was done in the Malaysia context.

\section{Methodology}

In order to test the hypotheses, a survey questionnaire was utilized, and designed on the basis of the extant research scales proven to exhibit good reliability and validity. Thus all measures were adapted from previous studies. Variables were measured via 5-point Likert scales, ranging from 'strongly disagree' to 'strongly agree.' All measurement items were adapted from previous studies and has undergone pre-test among 18 respondents from senior faculty members and students based at Kuala Lumpur. The questionnaire was assessed in terms of ease of understanding, logical consistencies, sequence of items, and contextual relevance and - where necessary - minor corrections were made. The main survey was administered online; with an introduction to $4 \mathrm{G}$ technology placed before the survey. The objective of the introductory page was 
to create awareness about $4 \mathrm{G}$ and not aiming to manipulate the respondents' views about the technology.

The targeted population are the $4 \mathrm{G}$ subscribers in Klang Valley. In this study, there are impossible to identify all the $4 \mathrm{G}$ subscribers of a population. Hence, the convenience sampling methods are used. A total of 150 people responded to the survey. However, only 95 completed the survey forms without any missing data. The cross sectional data collected through the survey were analysed using bivariate and descriptive analysis. Meanwhile, the reliability data of adoption level 4G is tested by using Cronbach's Alpha. According to [47], the Cronbach's alpha value greater than 0.7 is considered acceptable. The study achieved the Cronbach's alpha value of perceived usefulness, ease of use, attitude, entertainment value and behaviour intention was noted with $0.828,0.9,0.913,0.891$ and 0.886 respectively. Since, all variables were in high value for Cronbach's alpha, thus indicated good internal consistency of the items in the scale. Consequently, none of the items were deleted among these items. Moreover, all the items constructed had been used in past studies.

\section{Data Analysis and Results}

\subsection{Demographic Analysis and Descriptive Analysis}

The analysis of data was based on 95 respondents' feedback. The data consists of 57 female respondents $(60 \%)$ and 38 male respondents $(40 \%)$. Chinese is the majority respondents compared to others at $85.3 \%$ or 81 respondents, followed by Malays; reaching $10.5 \%$ or 10 respondents. Most of the respondents are at the aged of 19-24 years old, by $84.2 \%$ of the total respondents. The degree holders was the highest at $74.7 \%$ (71 respondents), while the rest are Master and $\mathrm{PhD}$ holders with $2 \%$ respectively. Students were the most as $4 \mathrm{G}$ subscribers at $56.8 \%$ or 54 respondents. This followed by executive, clerk and technician with $11.6 \%, 9.5 \%$ and $5.3 \%$ respectively. There are $57.9 \%$ or 55 respondents with their incomes less than RM1500 due to majority of the respondents were student. The second highest category is RM2001-RM3000 at $17.9 \%$ or 17 respondents. Among these respondents, the major subscribers with $69.5 \%$ or 66 respondents were live in Klang. KL areas was the second higher with 12 respondents or 12.6\%. The rest areas included Port Klang, Serdang, Shah Alam, Ampang, Bandar Baru Bangi, Bangi, Kangar, Kuala Kangsar, Kuala Selangor, and Petaling Jaya. Digi is the famous services provider compared to others which by $46.3 \%$ or 44 subscribers followed by Maxis, U Mobile and Celcom with 27.4\%, $13.7 \%$ and $10.5 \%$ respectively. Besides that, the most common internet usage is 6-7days per week with 68 respondents. In general, demographic profile showed that users are relatively young and generally well educated. From the result shows that $4 \mathrm{G}$ subscribers are moderately satisfied with their current services from the service provider with consists of 46 respondents or $48.4 \%$. There were 31 respondents who very satisfied of the current $4 \mathrm{G}$ services (32.6\%). 53 respondents out of 95 respondents (55.8\%) tend to subscribe $4 \mathrm{G}$ due to the delivers the faster mobile internet experience. The network capacities for more data per user are the second important reason for 18 respondents to subscribe $4 \mathrm{G}$ (18.9\%). The reasons for the $4 \mathrm{G}$ subscribers adopt $4 \mathrm{G}$ is because of the new base technology, low package cost for $4 \mathrm{G}$ services, potential for better voice quality and others with $9.5 \%, 8.4 \%, 4.2 \%$ and $3.2 \%$ respectively.

The overall mean for perceived usefulness was moderate with average mean 3.56 with the standard deviation is in range 0.75-0.89. Meanwhile, perceived ease of use recorded mean value of 3.71 (high) and achieved standard deviation in range $0.71-0.83$. The high mean average value obtained by attitude with the average mean score of 3.68 with standard deviation in range $0.76-0.83$. There are moderate average mean score for perceived entertainment value with 3.52, whilst; the standard deviation is in range 0.83-0.94. Behaviour intention factor attained mean of 3.77 and the standard deviation in the range between 0.74-0.81. The standard deviation for all the variable results shows the data point is closely grouped around the mean. From the normality analysis, all significant value of variables (P-values) was less than 0.005 . This indicates the data is not normally distributed. Therefore, non-parametric test were conducted using Spearman correlation test.

\subsection{Results}

Correlation is a bivariate measure to determine the strength of the relationship between two variables. 
The correlation coefficient of entertainment value is the highest among the variables. Perceived enjoyment showed moderate relationship with $44.4 \%$, while other factors were $35.4 \%$ (for Perceived of Use), $36.7 \%$ for Perceived Ease of Use and $38.6 \%$ for Attitude factor. The significant value of all variables is below 0.05 , which indicate significant influences. Results of this study clearly indicate support multimedia elements that can provide $4 \mathrm{G}$ services a big influence in the adaptation of technology. Therefore, the null hypotheses are rejected simultaneously. Table 6 lists the correlation result.

In assessing the impact of demographics on the adaptation of technology, this study used two methods of analysis Mann-Whitney U Test and Kruskal-Wallis. Mann-Whitney U test is used for two independent samples while Kruskal-Wallis $\mathrm{H}$ test is used for several independent samples. The tests were done for gender, academic qualification, monthly income and age toward behavioural intention. Dependent variable referred to behavioural intention, the two distributions of the independent variable for gender are male and female. The Mann-Whitney value is 1047.5 . Meanwhile, the asymptotic statistical significance level is 0.783 for 2tailed. Thus, the results shown there are no significant differences between gender and behavioural intention. Meanwhile for Kruskal-Wallis analysis, the outputs listed asymptotic statistical significance value for academic qualification, monthly income categories and age. All of the asymptotic value was greater than 0.05 , which means there is no significant difference between each demographic profile towards behavioural intention.

\section{Discussions and Conclusion}

This paper has examined the factors and user characteristics influencing intention to adopt 4G in Klang Valley, Malaysia. The results show that adoption intentions of $4 \mathrm{G}$ mobile services are dependent upon the influences of perceived usefulness, perceived ease of use and user attitude. Further, the results also highlighted that perceived enjoyment show strongest association toward adoption of $4 \mathrm{G}$ in terms of an individual's willingness to try a new technology. Overall, all hypotheses were supported. The demographic variables indicated that there is no significant difference in user's gender, age, academic qualification and monthly income when it comes to $4 \mathrm{G}$ adoptions [48]. This result means that the findings do not suffer from biases of gender, age, academic qualification and monthly income. Based from curve estimation analysis, the adoption level of 4G services in Klang Valley is $26 \%$. This result is concurrent with the current statistics report [7]. This findings here offer both theoretical and practical implications. First, this can help mobile service providers especially in designing attractive package and diffusion strategies. According to this research, service providers needed to publicize the superiority of speed of $4 \mathrm{G}$. For a more effective and efficient adoption of the 4G service, widespread and attractive awareness campaigns should be conducted, targeting potential users in order properly to inform them about the real benefits. Second, this study expanded and enriched a traditional TAM by further investigating factors associated with adoption of $4 \mathrm{G}$ service. Additionally, the results of this research should provide some insights into the understanding of diffusion of $4 \mathrm{G}$ mobile network.

The outcome of this study is expected to provide a better understanding on the pattern of adoption level towards subscribers' intention in Malaysia. The vitality of this study is allowed better market segment due to the analysis of subscribers' perspective pattern. The results revealed the perceived entertainment value is the most important that impacted element. In additional, the correlation coefficient of all variable is considered weak even though the results are statistically significant [49]. As 4G subscribers would like to continually use $4 \mathrm{G}$, hence, service providers should focus on reinforcing the relative advantage and entertaining attributes to promote the adoption of $4 \mathrm{G}$. Additionally, there is no effect on demographic profile towards subscribers' behavioral intention. Nevertheless, in the context of Malaysia, 4G still has some challenges to overcome in order to diffuse more widely.

\section{Acknowledgement}

Special thank for the cooperation given by the ORRIC in the success of this study. This preliminary study was sponsored by a fundamental research grant vot 1226 provided by the Malaysia Ministry of Education. This project is an ongoing research using the similar conceptual framework tested at different areas in main cities at Malaysia. Thus, the study helps the wireless service providers to enhance the services 
and coverage areas.

\section{References}

[1] A. Rawashdeh, "Adoption of 4G Mobile Services from the Female Student's Perspective: Case of Princess Nora University," Malaysian Online J. Educ. Technol., vol. 3, no. 1, pp. 12-27, 2015.

[2] C. Haitao, L., \& Xiaomin, "Multi-Agent Technology Applied to Mobile Communication," 2012.

[3] Brosly, "4G LTE in Malaysia - The Full Guide," 2014.

[4] B. Wu, "Digitimes Research: 3G to take up 53.1\% of mobile communication users in ASEAN in 2016," 2014. .

[5] CK Wong, "12 facts you might not know about mobile in Malaysia | eCommerceMILO," 2014.

[6] K.-B. Ooi, B. Lin, P.-L. Teh, and A. Y.-L. Chong, "Does TQM support innovation performance in Malaysia's manufacturing industry?,” J. Bus. Econ. Manag., vol. 13, no. 2, pp. 366-393, Apr. 2012.

[7] “Reinforcing Basics for Connected Services (Industry Perforance Report 2013)," Selangor Darul Ehsan, 2013.

[8] N. F. B. A. Aziz and N. A. M. Ali, “4G Coverage in Malaysia,” Int. J. Sci. Res., vol. 4, no. 1, pp. 1817-1823, 2015.

[9] M. Zendehdel, L. H. Paim, and N. Delafrooz, "Exploring Mobile 4G adoption in Malaysia," Int. J. Manag. Sci., vol. 5, no. 4, pp. 249-255, 2015.

[10] C.-F. Liew, "Full List of Maxis 4G LTE Coverage Areas," Tech News, 2013.

[11] B. H. Seng, "4G in Malaysia: What You Should Know - Leaping Post," 2013.

[12] S. Segan, "3G vs. 4G: What's the Difference? | News \& Opinion | PCMag.com,” 2015.

[13] S. Ganapathy, "The outlook for Malaysia’s ICT industry - Business Circle," 2014.

[14] M. S. Velmurugan and M. S. Velmurugan, "Consumers` Awareness, Perceived Ease of Use toward Information Technology Adoption in 3G Mobile Phones` Usages in India," Asian Journal of Marketing, vol. 8. pp. 1-23, 2014.

[15] J. Fernandez, "Billions wasted on MOE’s 'one-size-fits-all' IT policy | Free Malaysia Today,” 2015.

[16] J. J. Igbaria, M., Parasuraman, S.,\& Baroudi, “A motivational model of microcomputer usage,” 1996.

[17] K. Thomas, "Top 10 reasons to switch from 3G to 4G," 2015.

[18] S. K. dan M. Malaysia, "Reinforcing Basics For Connected Services," 2013.

[19] W. K. L. Wong Lai Soon, Neerjang Lama, Bobby Chai Boon Hui, "Joining the New Band: Factors Triggering the Intentions of Malaysian College and University Students to Adopt 4G Broadband," Inf. Manag. Bus. Rev., vol. 5, no. 2, pp. 58-65, 2013.

[20] M. E. Azira and S. Omar, "An Acceptance of 4G (Fourth Generation) Mobile Network in Malaysia," Int. J. Inf., vol. 3, no. 8, pp. 232-237, 2013.

[21] P. J. Kitchen, R. Martin, and N. Che-Ha, "Long term evolution mobile services and intention to adopt: a Malaysian perspective,” J. Strateg. Mark., no. January 2015, pp. 1-12, 2015.

[22] M. K. Littman, "Building Broadband,” Braodband Strateg. Handb., pp. 1-11, 2012.

[23] Y. L. Was, D. J. Sengupta, A. Kumar, and Divya, "Evolution of Mobile Wireless Communication Networks: $1 \mathrm{G}$ to 4G,” Desenbre 2010, vol. 7109, p. 5, 2010.

[24] E. Park and K. J. Kim, "User acceptance of long-term evolution (LTE) services: An application of extended technology acceptance model,” Progr. Electron. Libr. Inf. Syst., vol. 47, no. 2, pp. 188-205, 2013.

[25] O. G. Fadare, O. H. Babatunde, D. Theophilus, O. O. Lawal, A. E. Anglais, R. É. S. Umé, and F. French, "Behavioral Intention for Mobile Learning on 3G Mobile Internet Technology in South-West Part of Nigeria," World J Eng. Pure Appl. Sci., vol. 1, no. 2, pp. 19-28, 2011.

[26] F. D. Davis, "Perceived Usefulness, Perceived Ease Of Use, And User Acceptance," MIS Q., vol. 13, no. 3, pp. 319-339, 1989.

[27] O. P. Huda, Nurul , Rini Nova, Mardoni Yosi, "The Analysis of Attitudes, Subjective Norms , and Behavioral Control on Muzakki ’s Intention to Pay Zakah,” Int. J. Bus. Soc. Sci., vol. 3, no. 22, pp. 271-279, 2012.

[28] M. Ham, M. Jeger, and A. Frajman Ivković, "The role of subjective norms in forming the intention to purchase green food,” Econ. Res. Istraživanja, vol. 28, no. 1, pp. 738-748, 2015. 
[29] K.-B. Ooi, J.-J. Sim, K.-T. Yew, and B. Lin, "Exploring factors influencing consumers' behavioral intention to adopt broadband in Malaysia," Comput. Human Behav., vol. 27, no. 3, pp. 1168-1178, 2011.

[30] M. Reynolds, “Getting a grip: Critical systems for corporate responsibility,” vol. 407, no. February, pp. 391-408, 2008.

[31] N. Mohd Suki and N. Mohd Suki, "Exploring the Relationship Between Perceived Usefulness, Perceived Ease of Use, Perceived Enjoyment, Attitude and Subscribers' Intention towards using 3G Mobile Services," J. Inf. Technol. Manag., vol. XXII, no. 1, 2011.

[32] C. Iconaru, "The Moderating Role of Perceived Self-efficacy in the Context of Online Buying Adoption,” Broad Res. Accounting, Negot. Distrib., vol. 4, no. 1, pp. 20-29, 2013.

[33] G. H. Subramanian, "A Replication of Perceived Usefulness and Perceived Ease of Use Measurement," Decis. Sci., vol. 25, no. 5/6, pp. 863-874, 1994.

[34] K. J. Kim, "User acceptance of long-term evolution (LTE) servicesAn application of extended technology acceptance model,” Progr. Electron. Libr. Inf. Syst., vol. 47, pp. 188-205, 2013.

[35] F. Davis, R. Bagozzi, and P. Warshaw, "User acceptance of computer technology: a comparison of two theoretical models," Management science, vol. 35. pp. 982-1003, 1989.

[36] K. B. Ooi, J. J. Sim, K. T. Yew, and B. Lin, "Exploring factors influencing consumers' behavioral intention to adopt broadband in Malaysia," Comput. Human Behav., 2011.

[37] M. S. Abu Bakar and R. Bidin, "Engaging users using movie mobile advertising: Technology acceptance and purchase intention,” Asian Soc. Sci., vol. 10, no. 7, pp. 129-135, 2014.

[38] Mathieson, "Predicting User Intentions: Comparing the Technology Acceptance Model with the Theory of Planned Behavior,” Inf. Syst. Res., vol. 2, pp. 173-191, 1991.

[39] I. Ajzen, “Constructing a TPB Questionnaire : Conceptual and Methodological Considerations,” Time, vol. 2002, pp. 1-13, 2006.

[40] J. Y. L. Thong, S. J. Hong, and K. Y. Tam, "The effects of post-adoption beliefs on the expectation-confirmation model for information technology continuance,” Int. J. Hum. Comput. Stud., vol. 64, pp. 799-810, 2006.

[41] C. L. Hsu and H. P. Lu, "Consumer behavior in online game communities: A motivational factor perspective," Comput. Human Behav., vol. 23, pp. 1642-1659, 2007.

[42] C. Blanco, M. Blasco, and I. Azorín, "Entertainment and Informativeness as Precursory Factors of Successful Mobile Advertising Messages,” Commun. IBIMA, vol. 2010, pp. 1-10, 2010.

[43] D. L. R. Van Der Waldt, T. M. Rebello, and W. J. Brown, "Attitudes of young consumers towards SMS advertising,” African J. Bus. Manag., vol. 3, no. 9, pp. 444-452, 2009.

[44] C. Gardner and D. L. Amoroso, "Development of an instrument to measure the acceptance of Internet technology by consumers,” 37th Annu. Hawaii Int. Conf. Syst. Sci. 2004. Proc., vol. 00, no. C, pp. 1-10, 2004.

[45] L. H. Ho, C. L. Hung, and H. C. Chen, "Using theoretical models to examine the acceptance behavior of mobile phone messaging to enhance parent-teacher interactions," Comput. Educ., vol. 61, pp. 105-114, 2013.

[46] R. Fakhoury and B. Aubert, "Citizenship, trust, and behavioural intentions to use public e-services: The case of Lebanon,” Int. J. Inf. Manage., vol. 35, no. 3, pp. 346-351, 2015.

[47] J. C. Nunnaly, Psychometric Theory. New York: McGraw-Hill, 1978.

[48] B. Wenjing, “Consumer's adoption of technology innovations: the role of coping strategies,” 2006.

[49] J. W. Ong, "3G Services Adoption among University Students: Diffusion of Innovation Theory," Commun. IBIMA, vol. 3, pp. 114-121, 2008. 